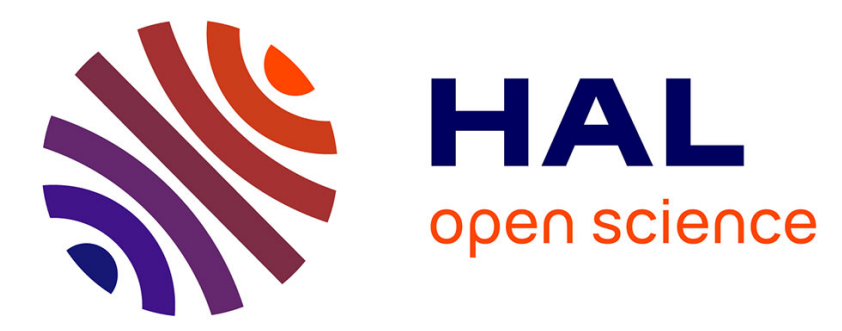

\title{
High Frequency Battery Impedance Measurements for EMI Prediction
}

Mohammad Sami Tabbakh, Florent Morel, Roberto Mrad, Youssef Zaatar

\section{To cite this version:}

Mohammad Sami Tabbakh, Florent Morel, Roberto Mrad, Youssef Zaatar. High Frequency Battery Impedance Measurements for EMI Prediction. EMC, Aug 2013, Denver, United States. pp.763-767, 10.1109/ISEMC.2013.6670512 . hal-00862617

\section{HAL Id: hal-00862617 https://hal.science/hal-00862617}

Submitted on 31 May 2019

HAL is a multi-disciplinary open access archive for the deposit and dissemination of scientific research documents, whether they are published or not. The documents may come from teaching and research institutions in France or abroad, or from public or private research centers.
L'archive ouverte pluridisciplinaire HAL, est destinée au dépôt et à la diffusion de documents scientifiques de niveau recherche, publiés ou non, émanant des établissements d'enseignement et de recherche français ou étrangers, des laboratoires publics ou privés. 


\title{
High Frequency Battery Impedance Measurements for EMI Prediction
}

\author{
Mohammad Sami Tabbakh ${ }^{\# 1}$, Florent Morel ${ }^{* 2}$, Roberto Mrad ${ }^{* 3}$, and Youssef Zaatar \#4 \\ \# Plateforme de Recherche en NanoSciences et NanoTechnologies \\ Lebanese University, Campus Fanar \\ 90656 Jdeidet, Lebanon \\ ${ }^{1} \mathrm{~ms}$. tabbakh@hotmail.com \\ ${ }^{4}$ yzaatar@ul.edu.lb \\ * AMPERE, UMR CNRS 5005 \\ Université de Lyon, École Centrale de Lyon \\ 36 avenue Guy de Collongue, 69134 Écully Cedex, France \\ 2 florent.moreldec-lyon.fr \\ 3 roberto.mraddec-lyon. fr
}

\begin{abstract}
In embedded applications which include power converters, the battery that provides the energy is a part of the EMI path. As conducted emissions generated by power converters spread into a large frequency band, the battery characterization should be extended to cover this range of frequencies. In this paper, a method to measure the battery impedance using an impedance analyzer is explained and applied to a cell-phone battery from $1 \mathrm{MHz}$ to $100 \mathrm{MHz}$. In this frequency range, measurements show that the battery impedance is unrelated to the battery state of charge and that a model including just inductances and resistances matches very well with the measured behavior. The measured impedance is validated by predicting the frequency spectrum of the battery's voltage when feeding a switched-mode power converter. The converter switches at $1.2 \mathrm{MHz}$ and the related harmonics extend beyond $100 \mathrm{MHz}$. The measured and predicted voltages match up to $80 \mathrm{MHz}$.
\end{abstract}

\section{INTRODUCTION}

In embedded systems such as electric or hybrid cars or portable electronic devices, the energy is provided by a battery. Power converters such as inverters for motors in electric cars [1] or class D audio amplifiers in cell phones [2] are connected to the battery. Power converters are responsible for conducted EMI, the battery is then a part of the noise path [3].

In order to reduce the perturbations at the battery level, an input filter (or a decoupling capacitor) is generally included between the converter and the battery. A proper design of the input filter requires the knowledge of the impedances at both sides [4] : the converter input impedance and the battery impedance. Also, even when an input filter is used, there are harmonic currents at high frequencies that flow in the battery [5]. These currents lead to radiated emissions, crosstalk [6], and voltage variations at the battery level that can disturb other embedded systems by common impedance coupling. For these reasons, the battery should be considered for EMC simulations in order to predict the conducted emissions as for non-embedded applications [7]. A battery model is also necessary in the case of battery chargers [8].

An equivalent electrical circuit that models the battery impedance can be obtained by a measurement followed by an identification process [9] (behavioral model) or by a device physical analysis [10] (knowledge model). Even in the case of a knowledge model, a measurement can be required in order to validate the model. This paper deals with the measurement of the battery impedance with an impedance analyzer for EMI prediction.

A short state of the art of battery measurements and modeling is given in Section II. The battery impedance measurement with an impedance analyzer is presented in Section III. This method is applied to a cell phone battery from $1 \mathrm{MHz}$ to $100 \mathrm{MHz}$. This measurement is used to obtain a behavioral model and, in Section IV, to predict the high frequency voltage when the battery supplies a switched-mode power supply (SMPS). Finally, a conclusion is given in Section V.

\section{Measurement techniques for batteries}

Traditionally, there exist two major techniques for battery modeling: electrochemical impedance spectroscopy (EIS) and charge/discharge dynamic modeling tests.

In battery EIS, just like usual impedance spectroscopy, the battery impedance spectrum is measured by applying an AC voltage and measuring the corresponding current (potentiostatic), or vice versa (galvanostatic) [11], [12]. In the galvanostatic configuration, a DC bias current is applied to the battery and in the potentiostatic configuration, a DC bias voltage, usually equal to the open circuit voltage of the battery under test, is applied to protect the battery from excessive discharge current through the measuring instrument. Thus, the EIS for batteries is implemented by the special instruments such as Solartron instruments. Such instruments operate at very low frequency ranges (from few $\mathrm{mHz}$ to some $\mathrm{kHz}$ ). This is because the phenomena under study such as state of charge (SOC), separator evaluation, and other reaction mechanisms are revealed only at low frequencies. Thus, considering that conducted EMI studies are done in moderate frequency ranges (on the order of tens of $\mathrm{MHz}$ ), traditional battery EIS are not suitable for EMI diagnosis. 
The second traditional battery modeling technique, the charge/discharge or dynamic modeling tests, is done to batteries in order to model their performance in terms of voltage, capacity fading, impedance and other parameters during charge cycle intervals and life cycle intervals by subjecting the battery to charge or discharge DC currents while monitoring some battery aspects such as the open circuit voltage and temperature [13], [14]. These studies do not provide any information about the impedance spectrum and thus are not useful for EMI modeling.

For EMC studies, the frequency bandwidth of previously presented instruments is not large enough. Moreover, usually, these devices are not at an EMC engineer's disposal. In [15], a vector network analyzer (VNA) is used to make measurements from $40 \mathrm{kHz}$ to $400 \mathrm{MHz}$. In this case, the battery is considered as a three-pole device (battery plus, battery minus and ground). The measured impedances correspond to the reflection and transmission parameters between the two ports but not to the battery impedance. In the case where the battery is not a threepole device but just a dipole, the method used in [15] would lead one to measure the battery impedance with a VNA. In [9], a dedicated power converter was designed in order to generate current ripples up to $20 \mathrm{kHz}$. In this paper, we use a method with a standard impedance analyzer.

\section{Measurement of A BatTery impedance With AN IMPEDANCE ANALYZER}

A battery cannot be directly plugged to an impedance analyzer because it would lead to a current in the measuring equipment [16]. This current can be heavy (and destructive for the impedance analyzer) in the case of a high voltage battery (for example in the case of the battery of an electric car). Thus, a $D C$ block (a two-port network that blocks the DC voltage) should be connected between the impedance analyzer and the battery (Fig. 1).

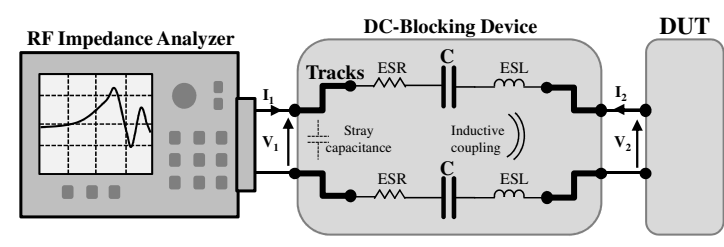

Fig. 1. Measurement set-up principle.

In [10] the battery impedances were measured up to $40 \mathrm{MHz}$ ( $10 \mathrm{kHz}$ for high voltage batteries) but the set up which protect the instrument is not presented. In [16], a capacitor is proposed as a DC block, the recommended frequency for the measurement is $1 \mathrm{kHz}$, the blocking capacitor impedance is considered as negligible and a direct measurement is supposed to give the battery impedance. Because of the considered frequency range in the present work (from $1 \mathrm{MHz}$ to $100 \mathrm{MHz}$ ), the behavior of capacitors is far from ideal due to their intrinsic limitations (equivalent series resistance, equivalent series inductance, etc.) and to the stray elements of the small PCB (printed circuit board) on which the capacitor is connected. Then the DC block cannot be neglected.

\section{A. Procedure}

The DC block can be modeled as a two-port network:

$$
\left[\begin{array}{l}
V_{1} \\
V_{2}
\end{array}\right]=\left[\begin{array}{ll}
Z_{11} & Z_{12} \\
Z_{12} & Z_{22}
\end{array}\right]\left[\begin{array}{l}
I_{1} \\
I_{2}
\end{array}\right]=Z_{\boldsymbol{D C}}\left[\begin{array}{l}
I_{1} \\
I_{2}
\end{array}\right] .
$$

When a device under test (DUT), having $Z_{D U T}$ as an impedance, is connected to the port $2, V_{2}=-Z_{D U T} I_{2}$. Then the impedance measured by the impedance analyzer $\left(Z_{I A}\right)$ is given by:

$$
Z_{I A}=\frac{V_{1}}{I_{1}}=Z_{11}-\frac{Z_{12}^{2}}{Z_{22}-Z_{D U T}} .
$$

Three initial measurements with three different $Z_{D U T}$ values are required in order to identify the $Z_{D C}$ elements. A method is given in [17]; in the present work, we choose another method that does not require a change of connections between the DC block and the impedance analyzer.

- For $Z_{\text {init }}, Z_{D U T}$ is an open circuit $\left(\left|Z_{D U T}\right| \rightarrow \infty\right)$.

- For $Z_{\text {init }_{2}}, Z_{D U T}$ is a short circuit $\left(\left|Z_{D U T}\right| \rightarrow 0\right)$.

- For $Z_{\text {init }}, Z_{D U T}$ is a known impedance $\left(Z_{D U T}=Z_{s t d}\right)$.

Here $Z_{\text {std }}$ is a known impedance that should be close to the expected battery impedance.

Using the upper three measurements in (3) allows us to compute the elements of $Z_{D C}$ :

$$
\begin{aligned}
Z_{11} & =Z_{\text {init }_{1}} \\
Z_{12} & =\sqrt{\frac{\left(Z_{\text {init }_{1}}-Z_{\text {init }_{2}}\right)\left(Z_{\text {init }_{1}}-Z_{\text {init }_{3}}\right)}{Z_{\text {init }_{3}}-Z_{\text {init }_{2}}} Z_{\text {std }}} \\
Z_{22} & =\frac{Z_{\text {init }_{1}}-Z_{\text {init }_{3}}}{Z_{\text {init }_{3}}-Z_{\text {init }_{2}}} Z_{\text {std }} .
\end{aligned}
$$

Finally, solving (2) and using the results of (3) lead to a computed $Z_{c o m p}$ (4) that is theoretically equal to $Z_{D U T}$ :

$$
Z_{\text {comp }}=\frac{\left(Z_{\text {init }_{1}}-Z_{\text {init }_{3}}\right)\left(Z_{I A}-Z_{\text {init }_{2}}\right)}{\left(Z_{\text {init }_{3}}-Z_{\text {init }_{2}}\right)\left(Z_{\text {init }_{1}}-Z_{I A}\right)} Z_{s t d} .
$$

This procedure can be seen as a custom compensation procedure. Indeed, impedance analyzers propose a compensation procedure in order to take into account that the measurement plane can differ from the calibration plane [16]. In the present case, the standard compensation procedure will fail because the DC block impedance is very different from the one of a test fixture or a cable.

\section{B. Examples of Procedure Application}

Results shown in this section were obtained with the Agilent E4991a impedance analyzer [18].

1) Procedure validation with a known impedance: In order to check the validity of the method, a comparison should be made between known impedance values considered as references (in this case simple resistors were chosen), and the calculated ones using the method presented in Section III-A. The reference resistors are mounted on small PCBs in order to avoid variations in the leads positions, and thus avoiding variations in their parasitic impedances. The resistor, the PCB, 
and the corresponding connectors constitute the reference device.

The comparison is done as follows: first the reference device is measured directly with the 4991a impedance analyzer following the procedure described in the instrument data sheet $\left(Z_{\text {ref }}\right)$; second, the same device is measured when preceded by the DC block ( $Z_{I A}$ with $\left.Z_{D U T}=Z_{r e f}\right)$; hereafter equation (4) permits to compute the device impedance $\left(Z_{\text {comp }}\right)$ from $Z_{I A}$; finally comparing $Z_{r e f}$ to $Z_{\text {comp }}$ validate the compensation technique.

Fig. 2 shows results when $Z_{s t d}$ (the impedance used for the measurement of $\left.Z_{\text {init } 3}\right)$ is a $0.5 \Omega$ resistor and the DUT $\left(Z_{\text {ref }}\right)$ is a $1 \Omega$ resistor. It can be seen that the computed impedance $Z_{\text {comp }}$ and the impedance directly measured $Z_{\text {ref }}$ match very well all over the considered frequency range. Also, it can be seen that the DC block is not negligible since $Z_{\text {comp }}$ is very different from $Z_{I A}$.
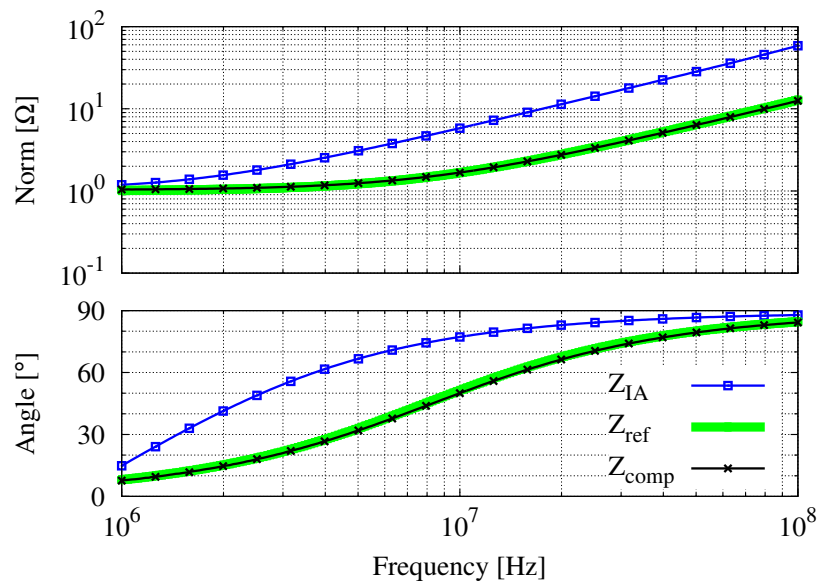

Fig. 2. Impedances for the procedure validation.

2) Results for a cell-phone battery: The procedure was applied to a Nokia BL-5CA battery dedicated to cell-phones. This Li-ion battery has a capacity of $700 \mathrm{mAh}$ and nominal voltage of $3.7 \mathrm{~V}$. Results are shown on Fig. 3.
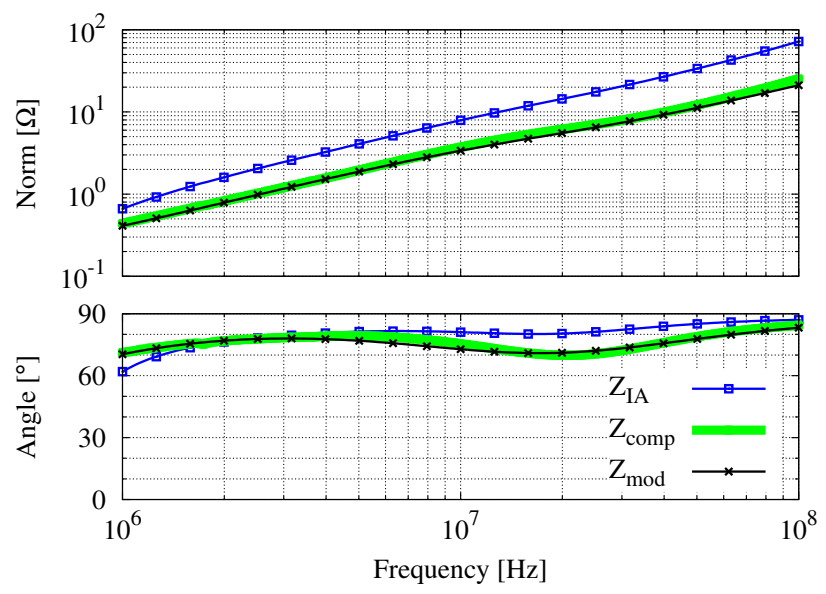

Fig. 3. Battery impedance Measurement.
The inductive behavior of the battery is coherent with the analysis and the results from [9], [10]. As in [10], experience shows that the impedance does not change when the state of charge changes. It can be supposed that, at high frequencies, the impedance is more related to electrodes and connections than to electrochemical phenomena.

In order to use the battery impedance in software simulations, an equivalent circuit model should be established. An equivalent circuit is shown in Fig. 4 . In this model, $L_{1}$ and $R_{1}$ model the stray inductance and the resistance of the battery and of its connections. $L_{2}$ and $R_{2}$ are added in order to take into account the skin effect [9], [10].

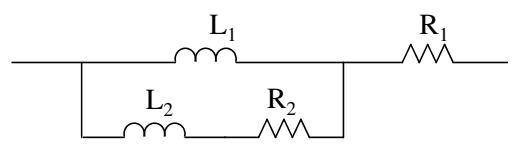

Fig. 4. Battery impedance model.

The elements of the equivalent circuit are calculated by least-squares error algorithm. The comparison between the equivalent circuit impedance $\left(Z_{\text {mod }}\right)$ and the measured one $\left(Z_{\text {comp }}\right)$ (Fig. 3) shows that this model describes very well the behavior of the battery under consideration.

\section{EXPERIMENTAL VALIDATION}

For the experimental validation a DC/DC step-up converter VT-0312 (Fig. 5) from Musimi was used for battery voltage prediction. This converter provides $12 \mathrm{~V}$ with an input voltage between 2.7 and $5 \mathrm{~V}$. The maximum input current is $70 \mathrm{~mA}$. The switching frequency is $1.2 \mathrm{MHz}$.

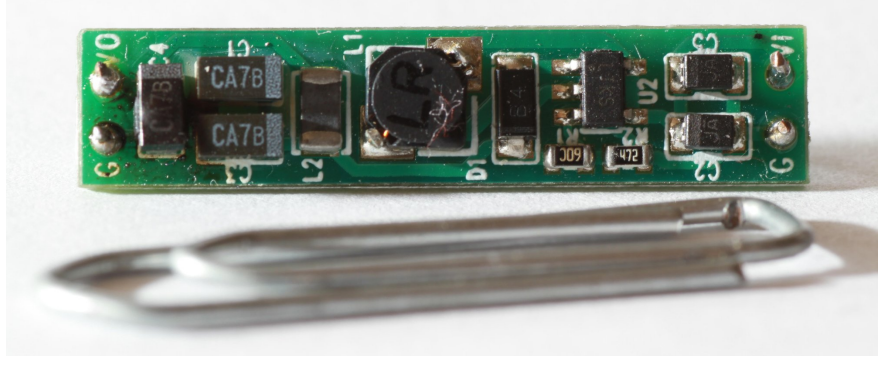

Fig. 5. Converter used for the experimental validation.

The DC/DC board was mounted on an another PCB that connects the battery to the converter input, and the load to the converter output. The PCB also has holes around the track connected to the plus pin of the battery in order to easily plug a current probe for current sensing and has pins at the battery plus/minus for voltage sensing.

Current at the converter input and voltage at the battery connector were measured. The current is used for voltage calculation and the measured voltage is used for comparison (Fig. 6).

The validation bench consisted of a Tektronix P6022 passive current probe with a bandwidth of [935 Hz-120 MHz], an Agilent 1141A differential active voltage probe with a 


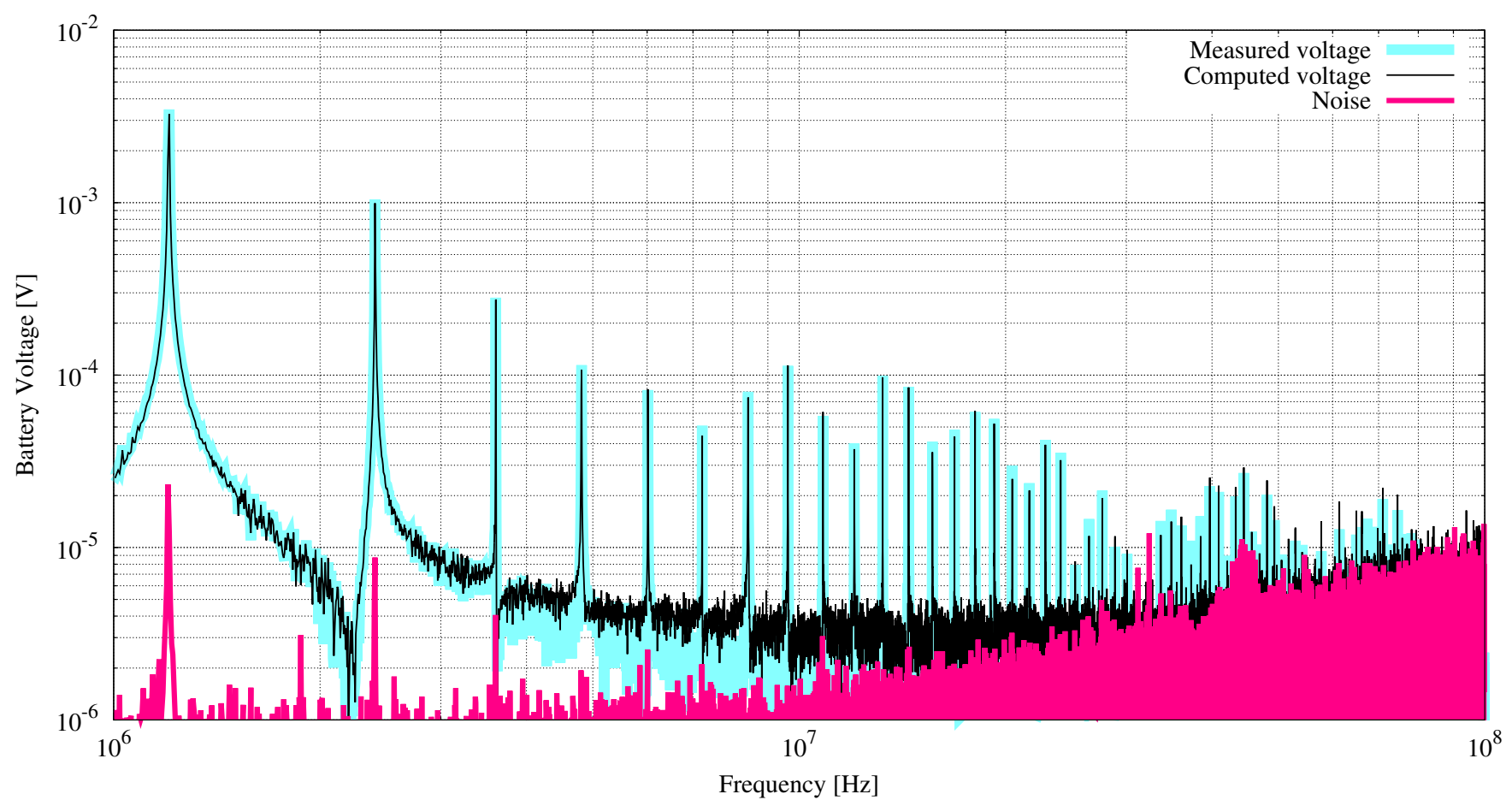

Fig. 7. Magnitude of the battery voltage FFT when feeding the SMPS.

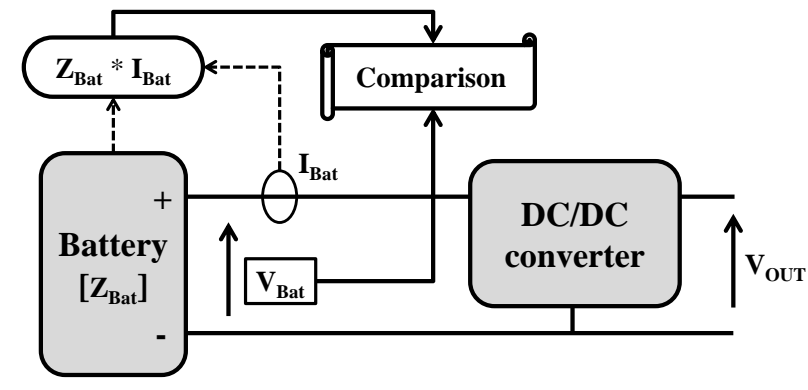

Fig. 6. Validation process.

bandwidth of $200 \mathrm{MHz}$, and a Lecroy high resolution HRO 64Zi digital oscilloscope with a bandwidth of $400 \mathrm{MHz}$, and having a 12 bits vertical quantization, in order to reduce the noise floor imposed by the oscilloscope digitization.

The validation was done as follows. First, the bench was placed in an anechoic chamber in order to reduce the environmental perturbations. Second, the current and voltage at the converter input were measured in the time domain, then their spectra were computed using the fast Fourier transform (FFT). Finally, the measured current spectrum was multiplied by the measured battery impedance in order to calculate the voltage spectrum. Results are shown in Fig. 7.

Results show that the converter switching at $1.2 \mathrm{MHz}$ have harmonics all over the considered frequency band. Fig. 7 also shows that the calculated voltage match with the measured ones, at least up to $80 \mathrm{MHz}$. However, beyond $80 \mathrm{MHz}$ the noise floor is hiding the voltage spectra which prevents a results comparison. The "Noise" curve in Fig. 7 is the maximum value between the "voltage noise" (voltage measured when plugging both pins of the differential probe to the minus pin) and the "calculated voltage noise" (voltage obtained by multiplying the measured current when the current probe is unplugged and kept near the sensing area by the measured battery impedance) on each frequency point. Thus, "Noise" represents the noise floor over the entire frequency band imposed by the measuring instrumentation.

\section{CONClusion}

In this paper a method to measure and model battery impedance has been presented and validated up to $80 \mathrm{MHz}$. This method uses an impedance analyzer which is a common instrument for EMC engineers as opposed to instruments dedicated to impedance spectroscopy. Also an impedance analyzer allows measurements at higher frequencies than those of instruments for electrochemical science. Future work will be dedicated to include a model of the battery impedance in a circuit simulation software in order to predict battery's voltage and current with simulations.

\section{REFERENCES}

[1] D. Labrousse, B. Revol, and F. Costa, "Common-mode modeling of the association of $N$-switching cells: Application to an electric-vehicle-drive system," Power Electronics, IEEE Transactions on, vol. 25, no. 11, pp. 2852-2859, nov. 2010.

[2] R. Mrad, F. Morel, G. Pillonnet, C. Vollaire, and D. Labrousse, "Differential passive circuit modelling with pentapole impedance matrices - Application to an integrated audio switching amplifier for portable devices," in EMC Europe 2011 York, sept. 2011, pp. 304-309. 
[3] S. Guttowski, S. Weber, E. Hoene, W. John, and H. Reichl, "EMC issues in cars with electric drives," in Electromagnetic Compatibility, 2003 IEEE International Symposium on, vol. 2, aug. 2003, pp. 777782.

[4] V. Tarateeraseth, K. Y. See, F. Canavero, and R. Chang, "Systematic electromagnetic interference filter design based on information from incircuit impedance measurements," Electromagnetic Compatibility, IEEE Transactions on, vol. 52, no. 3, pp. 588-598, aug. 2010.

[5] S. Adami, R. Mrad, F. Morel, C. Vollaire, G. Pillonnet, and R. Cellier, "Conducted EMI of integrated switching audio amplifier for mobile phone applications," in Electromagnetic Compatibility of Integrated Circuits (EMC Compo), 2011 8th Workshop on, nov. 2011, pp. 142147.

[6] S. Weber, S. Guttowski, E. Hoene, W. John, and H. Reichl, "EMI coupling from automotive traction systems," in Electromagnetic Compatibility, 2003. EMC '03. 2003 IEEE International Symposium on, vol. 1, may 2003, pp. 591-594.

[7] B. Revol, J. Roudet, J.-L. Schanen, and P. Loizelet, "Emi study of three-phase inverter-fed motor drives," Industry Applications, IEEE Transactions on, vol. 47, no. 1, pp. 223 -231, jan.-feb. 2011.

[8] D. Hamza, M. Pahlevaninezhad, and P. Jain, "Implementation of a novel digital active EMI technique in a DSP-based DC-DC digital controller used in electric vehicle (EV) battery charger," Power Electronics, IEEE Transactions on, vol. PP, no. 99, p. 1, 2012.

[9] J. Wang, K. Zou, C. Chen, and L. Chen, "A high frequency battery model for current ripple analysis," in Applied Power Electronics Conference and Exposition (APEC), 2010 Twenty-Fifth Annual IEEE, feb. 2010, pp. 676-680.

[10] E. Hoene, S. Guttowski, R. Saikly, W. John, and H. Reichl, "RFproperties of automotive traction batteries," in Electromagnetic Compatibility, 2003. EMC '03. 2003 IEEE International Symposium on, vol. 1, may 2003, pp. 425-428.
[11] A. Lasia, "Electrochemical impedance spectroscopy and its applications," Sherbrook University, Tech. Rep., 2006, available online.

[12] S. Buller, M. Thele, R. De Doncker, and E. Karden, "Impedance-based simulation models of supercapacitors and $\mathrm{Li}$-ion batteries for power electronic applications," Industry Applications, IEEE Transactions on, vol. 41, no. 3, pp. 742-747, may-june 2005

[13] O. Erdinc, B. Vural, and M. Uzunoglu, "A dynamic lithium-ion battery model considering the effects of temperature and capacity fading," in Clean Electrical Power, 2009 International Conference on, june 2009, pp. 383-386.

[14] L. Gao, S. Liu, and R. Dougal, "Dynamic lithium-ion battery model for system simulation," Components and Packaging Technologies, IEEE Transactions on, vol. 25, no. 3, pp. 495-505, sep 2002.

[15] M. Reuter, S. Tenbohlen, W. Kohler, and A. Ludwig, "Impedance analysis of automotive high voltage networks for EMC measurements," in EMC Europe 2011 York, sept. 2011, pp. 106-111.

[16] "Agilent impedance measurement handbook - a guide to measurement technology and techniques," Agilent Technologies, Tech. Rep., 2009, 4th edition.

[17] C. Jettanasen, F. Costa, and C. Vollaire, "Common-mode emissions measurements and simulation in variable-speed drive systems," Power Electronics, IEEE Transactions on, vol. 24, no. 11, pp. 2456-2464, nov. 2009.

[18] “Agilent E4991A RF impedance/material analyzer - data sheet," Agilent Technologies, Tech. Rep., 2011. 